\title{
Role of MRI Modalities in Assessment of Cystic Lesions of the Female Pelvis
}

\author{
NEHAL E.A. ELSHEBL, M.Sc.; HESHAM M.A. MANSOUR, M.D. and MENA E. YOUSEEF, M.D. \\ The Department of Radio-Diagnosis, Faculty of Medicine, Ain Shams University
}

\begin{abstract}
Background: Cystic disease of the female pelvis is common, mostly of ovarian origin and it can range from simple or functional ovarian cysts to malignant tumors. Determining whether the pelvic cystic lesion is of ovarian or non-ovarian origin and the nature of the lesion, whether benign or malignant is of great importance in order to plan adequate therapeutic procedures, and may influence patient's management. MRI can provide valuable information such as lesion's morphology, signal intensity and post contrast enhancement, allowing a more complete evaluation.
\end{abstract}

Aim of Study: To describe the role of conventional Magnetic Resonance Imaging (MRI) in assessment of cystic lesions of the female pelvis and assess the ability of conventional MRI to successfully differentiate benign from malignant lesions.

Patients and Methods: It is a prospective \& descriptive study of conventional MRI of the pelvis in 20 female patients, aged between 18-60 years; referred to the MRI unit based on preliminary ultrasound detection of a complex cystic lesion, GI-RADS category 3 or more. Clinical evaluation was preformed by the referring physician. MRI pelvis was done for all patients with further pathologic correlation. The study was conducted at Ain Shams University Hospitals over a period of 6 months.

Results: Conventional MRI also suggested benign pathology of fourteen out of the twenty one studied lesions; all of them were true benign. MRI had shown $93.3 \%$ sensitivity, $100 \%$ specificity, $95.2 \%$ accuracy, $100 \%$ positive predictive value and $85.7 \%$ negative predictive value in its individual performance during the assessment of the included adnexal masses.

Conclusion: Conventional MR imaging proved to exhibits high sensitivity and specificity for differentiating benign from malignant complex adnexal lesions.

Key Words: MRI - Cystic lesions - Female pelvis.

Correspondence to: Dr. Nehal E.A. Elshebl, The Department of Radio-Diagnosis, Faculty of Medicine,

Ain Shams University

\section{Introduction}

CYSTIC disease of the female pelvis is common and it can range from simple or functional ovarian cysts to malignant tumors. Many pelvic lesions are a diagnostic challenge, given their proximity to a variety of pelvic structures and the overlap of specific imaging features among different diagnoses [1]. Ultrasound (US) is often the first imaging study performed in the evaluation of a suspected ovarian lesion because it's widely available, well accepted by patients, non-invasive and of low cost [2]. However, ultrasound may be limited by poor acoustic windows and poor depth of penetration, preventing characterization of some lesions. CT is limited in the pelvis by a lack of soft-tissue contrast [1].

MRI has become an important modality in the evaluation of female pelvic lesions. It is considered the next step in the imaging assessment of benign disease of the uterus and adnexa and is becoming the primary imaging modality for evaluating gynaecological malignancies [3].

The multi-planer imaging capability of MRI, superior soft tissue contrast and large field of view offer distinct advantages over both Ultrasound and CT (Computer Tomography) in the assessment of gynaecologic abnormalities [2,3].

The use of Magnetic Resonance (MR) imaging in differentiation between benign and malignant adnexal masses might be of great value in the diagnostic workup of sonographically indeterminate cystic lesions, since preserving fertility is of particular importance [4].

MRI has been shown to be more specific and accurate than ultrasound for characterizing adnexal lesions. By using a systematic approach to complex pelvic lesions, incorporating the patient's clinical and surgical history, and using MRI to identify the 
anatomic origin, shape, composition, and enhancement pattern of the mass, a short meaningful differential diagnosis, and often a definitive diagnosis, can be made [1].

Aim of this study was to describe the role of conventional Magnetic Resonance Imaging (MRI) in assessment of cystic lesions of the female pelvis and assess the ability of conventional MRI to successfully differentiate benign from malignant lesions.

\section{Patients and Methods}

\section{Patients:}

This is a prospective \& descriptive study of MRI of the pelvis, that included 20 female patients, aged between $18-60$ years (mean age $36 \pm 12.61$ SD). Patients were referred from the Obstetrics and Gynecology Department to the Radiology Department at Ain Shams University Hospitals and El-Nozha International Hospital, based on preliminary detection of a complex cystic lesion by transabdominal/transvaginal ultrasound. Clinical evaluation was preformed by the referring physician and MRI of the pelvis was done for all patients with further pathologic correlation. The study was conducted over a period of 6 months from June 2019 December 2019. The university ethics committee reviewed our protocol and approved the study. All patients signed an informed consent.

\section{Inclusion criteria:}

Adult females, aged 18 or more, diagnosed with complex cystic lesion by US exam, GI-RADS [5] category 3 or more.

\section{Exclusion criteria:}

- Pediatric age groups.

- Impaired renal functions:

- Serum creatinine level $\geq 2 \mathrm{mg} / \mathrm{dL}$.

- GRF $<30 \mathrm{~mL} / \mathrm{min} / 1.73 \mathrm{~m}^{2}$.

\section{Methodology:}

All cases had been subjected to the following:

1- Full history taking with a special emphasis on:

- Age.

- Parity.

- Past history of gynecological troubles or operations.

2- Trans abdominal and/or trans vaginal U/S study.

3- Conventional MRI study.

Institutional ethical committee approval was obtained for this study.

\section{Patient preparation:}

Intravenous administration of $10 \mathrm{mg}$ of an antispasmodic drug was given immediately before MR imaging to reduce bowel peristalsis.

\section{MR imaging:}

MRI of the pelvis was performed at a 1.5-T MR imaging unit (Achieva, Philips medical system) at Ain Shams University Hospitals \& (Optima 360, GE healthcare) at El-Nozha International Hospital. All the patients were imaged in the supine position with the aid of phased-array body coil.

Conventional MR imaging protocol:

- Axial T1-weighted (TR/TE=700-750/10-20).

- Axial T2-weighted (TR/TE=3000-3700/90-110).

- Sagittal T2-weighted.

- Coronal T2-weighted.

- Post contrast fat suppressed T1WI with slice thickness $(5-15 \mathrm{~mm})$, gap (1-2mm) field of view $(20-40 \mathrm{~cm})$ and matrix size $(128 \cdot 256)$, after administration of gadolinium diethylene triaminopentaacetic acid intravenously by power injector at a dose of $0.1 \mathrm{mmol} / \mathrm{kg}$ body weight with flow rate of $1.5 \mathrm{~mL} / \mathrm{second}$ followed by $30 \mathrm{~mL}$ saline flush at the same flow rate.

\section{MR imaging analysis:}

MR images were analyzed for the following: MR appearance of the tumor; either pure cystic or complex lesion, involvement of one or both ovaries, size of the lesion, signal intensity of the tumor, enhancement of the solid component if present, wall thickness and regularity of the tumor and its enhancement, presence of vegetations and septations, their enhancement pattern and their size, presence of ascites, presence of infiltrated pelvic or para aortic lymph nodes, involvement of other pelvic organs, and presence of peritoneal and omental deposit.

Post contrast images were used for the recognition of enhancement of the solid component, the tumor wall, septations and vegetations.

For classifying a cystic lesion as malignant we followed the criteria used by Valentini et al. [6].

- Solid vegetations more than $1 \mathrm{~cm}$.

- Thick septa $>3 \mathrm{~mm}$.

- Areas of necrosis and breaking down.

- Signs of tumor spread for staging: Enlarged lymph nodes, ascites, peritoneal and omental deposit. 


\section{Results}

This study included twenty-one (21) ovarian lesions in twenty (20) patients ( 1 case showed bilateral masses). The patients' age ranged from 18 to 60 years old (mean age $36 \pm 12.61 \mathrm{SD}$ ). The final diagnosis based on surgical pathological types of all patients is listed in (Table 1). Fifteen (71.4\%) of the 21 complex cystic lesions were benign, four (19\%) were malignant and two cases $(9.5 \%)$ were borderline.

Table (2) shows the conventional MRI characteristics among different groups. On T2 weighted images, the solid component was observed in all four malignant lesions with statistically significant difference $(p<0.025)$. Also the presence of vegetations, ascites and regional lymphadenopathy was more frequent in malignant than benign lesions
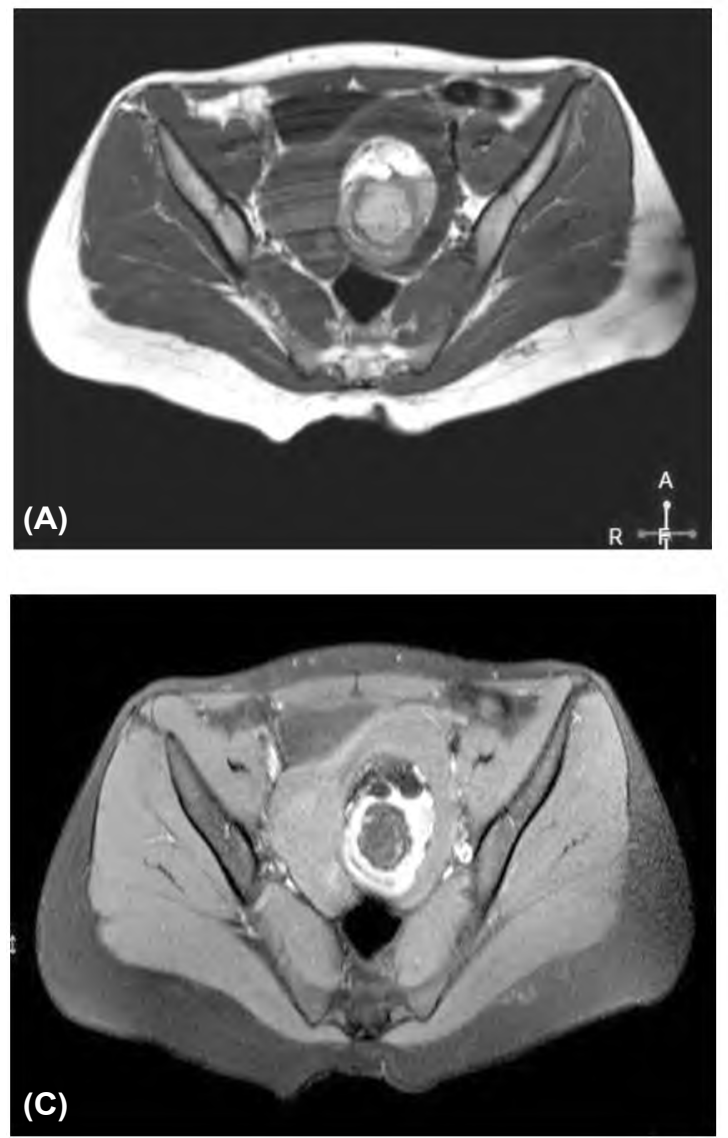

with significant difference ( $p$-value $<0.001,<0.01$ and $<0.001$ respectively). There were four main morphological types detected, complex cystic lesion (38.1\%), multilocular cyst (42.9\%), bilocular cyst $(14.3 \%)$ and heterogenous multicystic lesion (4.8\%). Morphology showed no statistically significant difference $(p<0.05)$.

In general, out of the 4 malignant lesions conventional MRI parameters suggested malignant pathology in three lesions. Conventional MRI also suggested benign pathology in 14 out of the 21 studied lesions; all of them were true benign. The overall sensitivity, specificity, Positive Predictive Value (PPV), Negative Predictive Value (NPV) and accuracy of MRI in its individual performance during the assessment of the included adnexal masses were $93.3 \%, 100 \%, 100 \%, 85.7 \%$, and $95.2 \%$ respectively.
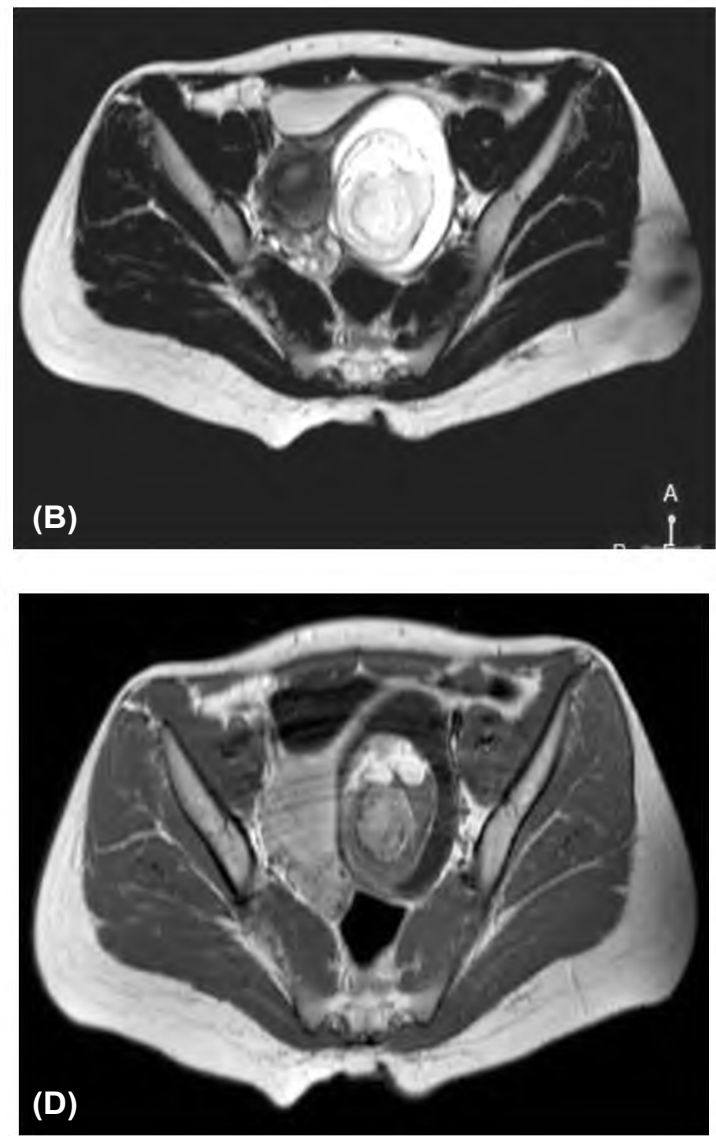

Fig. (1): A 18 years old female patient with left adnexal complex cystic mass on ultrasound. (A) Axial T1 WI, (B) Axial T2 WI, (C) Axial T1 fat sat, (D) Axial T1 post-contrast. The lesion shows rather rounded solid component in the center surrounded by cystic component. The cystic component elicits hypo intense signal in T1WI and hyper intense signal in T2WI, while the solid component inside shows areas of bright signal in T1WI and intermediate signal in T2WI suppressed on fat suppression (STIR). No solid enhancing masses seen on post contrast. Final diagnosis: Mature cystic teratoma. 

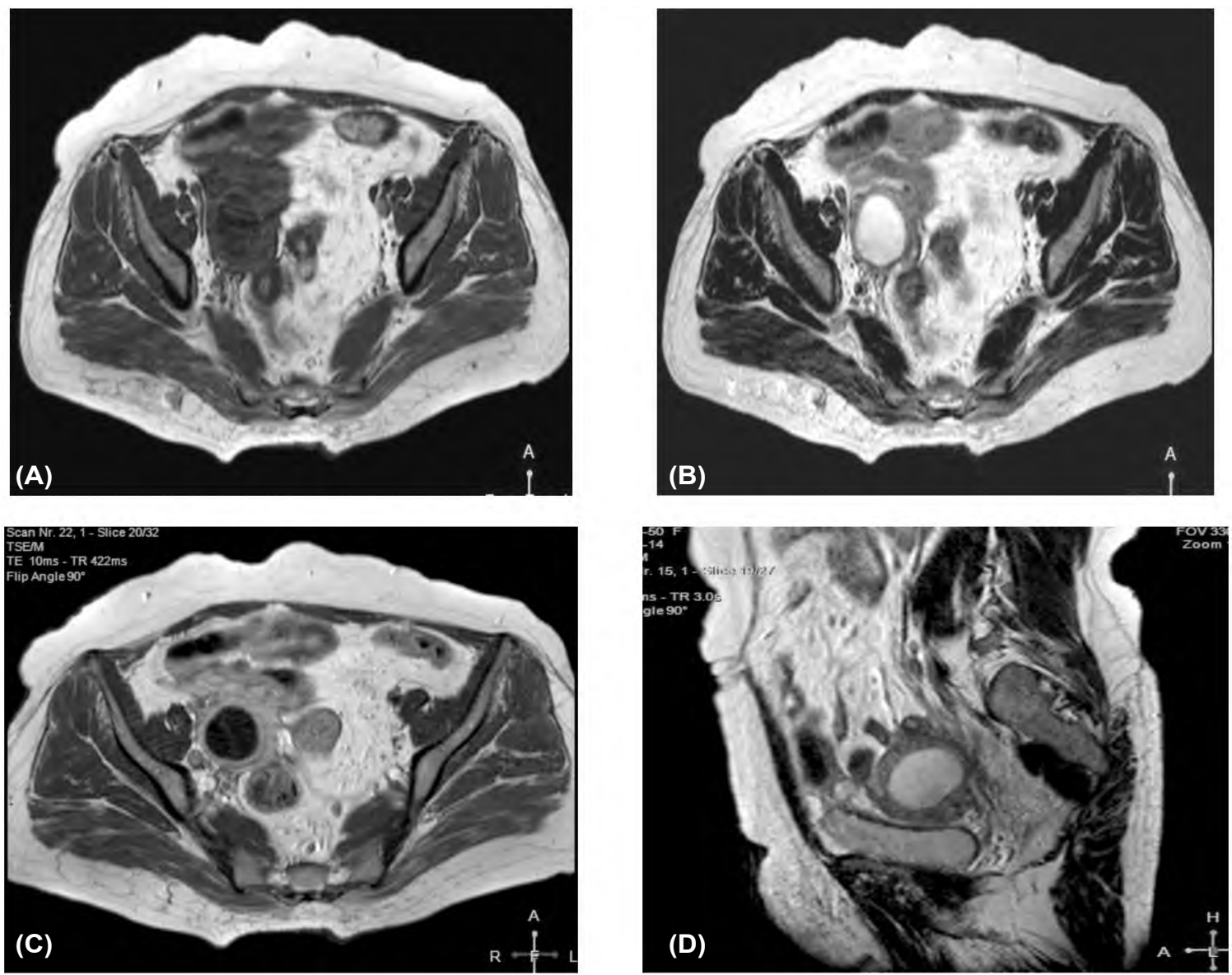

Fig. (2): Female patient aged 60 years, with right adnexal complex cystic mass with soft tissue component on ultrasound. (A) Axial T1 WI, (B) Axial T2 WI, (C) Axial T1 post contrast, (D) Sagittal T2. The lesion shows central cystic component with hypo intense signal in T1WI and hyper intense signal in T2WI, it also shows solid component with intermediate signal in both T1WI \& T2WI and faint contrast enhancement in post contrast image. The mass is seen inseparable from adjacent bowel loops. Final diagnosis: Serous cyst adenocarcinoma.

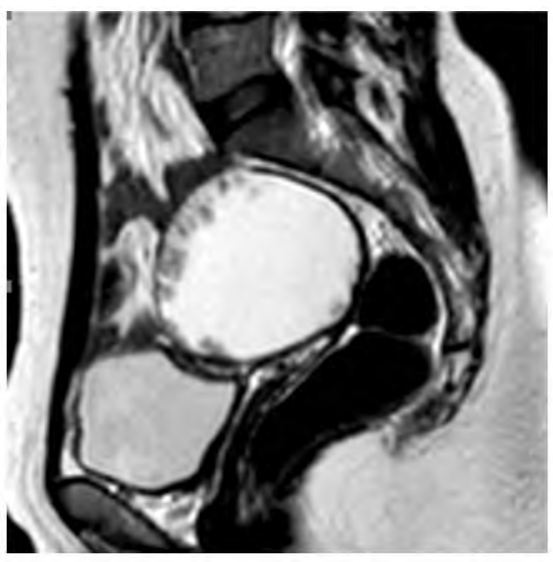

(A)

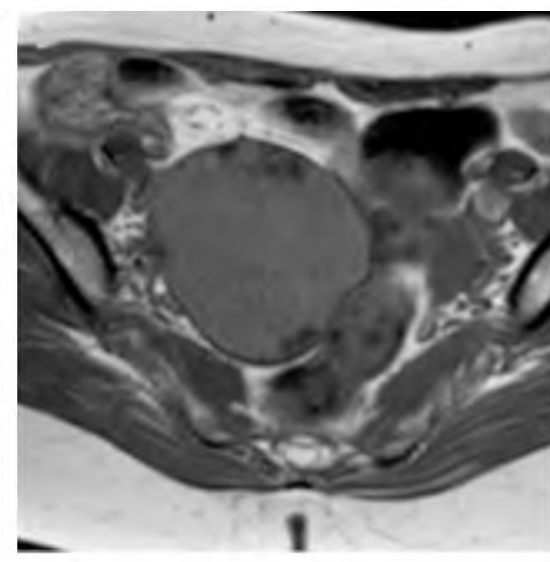

(B)

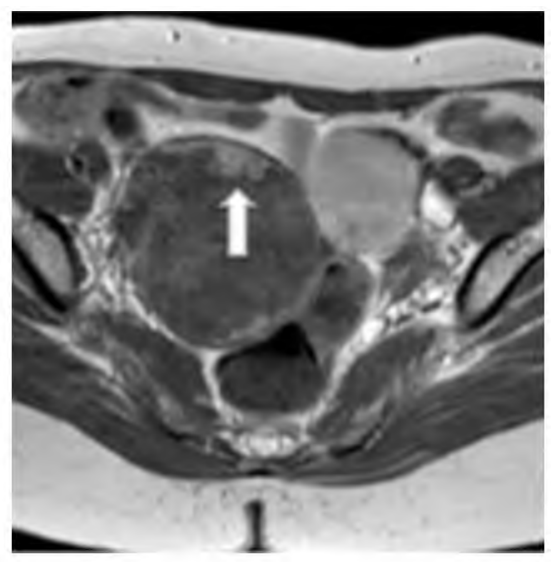

(C)

Fig. (3): A 46-year-old female patient with accidentally discovered right adnexal cystic lesion by ultrasound. (A) Sagittal T2 WI, (B) Axial T1 WI, (C) Axial T1 post contrast. The lesion elicits intermediate T1 and high T2 signals denoting high proteinacous contents. T1 post contrast shows small faintly enhancing mural vegetations that reach $1.5 \mathrm{~cm}$ in thickness. Final diagnosis: Borderline papillary serous cystadenoma (epithelial tumor). 
Table (1): Confirmed histopathological diagnosis of the examined lesions.

\begin{tabular}{lll}
\hline Pathology & No. & $\%$ \\
\hline Benign: & 15 & 71.4 \\
Mature cystic teratoma & 5 & 33.3 \\
Serous cyst-adenoma & 3 & 20.0 \\
Tubo-ovarian abscess & 4 & 26.7 \\
Endometrioma & 2 & 13.3 \\
Mucinous cyst adenoma & 1 & 6.7 \\
Malignant: & 4 & 19.0 \\
Cyst adenocarcinoma & 2 & 50.0 \\
Granulose cell tumor & 1 & 25.0 \\
Immature teratoma & 1 & 25.0 \\
Borderline: & 2 & 9.5 \\
Papillary cyst adenoma & 2 & 100.0 \\
\hline
\end{tabular}

Table (2): Conventional MRI characteristics of the studied patients.

\begin{tabular}{|c|c|c|c|c|c|c|}
\hline & \multicolumn{6}{|c|}{ MRI } \\
\hline & \multicolumn{2}{|c|}{ Benign } & \multicolumn{2}{|c|}{ Malignant } & \multicolumn{2}{|c|}{ Borderline } \\
\hline & No. & $\%$ & No. & $\%$ & No. & $\%$ \\
\hline \multicolumn{7}{|l|}{ Morphology: } \\
\hline Complex cyst & 6 & 42.9 & 2 & 66.7 & 0 & 0.0 \\
\hline Multi-locular cyst & 5 & 35.7 & 1 & 33.3 & 3 & 75.0 \\
\hline Bilocular cyst & 3 & 21.4 & 0 & 0.0 & 0 & 0.0 \\
\hline Multiple cysts & 0 & 0.0 & 0 & 0.0 & 1 & 25.0 \\
\hline \multicolumn{7}{|l|}{ Solid comp.: } \\
\hline No & 10 & 71.4 & 0 & 0.0 & 2 & 50.0 \\
\hline Yes & 4 & 28.6 & 3 & 100.0 & 2 & 50.0 \\
\hline \multicolumn{7}{|l|}{ Papillary vegetations: } \\
\hline No & 14 & 100.0 & 0 & 0.0 & 2 & 50.0 \\
\hline Yes & 0 & 0.0 & 3 & 100.0 & 2 & 50.0 \\
\hline \multicolumn{7}{|l|}{ Side: } \\
\hline Right & 5 & 35.7 & 2 & 66.7 & 2 & 50.0 \\
\hline Left & 7 & 50.0 & 1 & 33.3 & 2 & 50.0 \\
\hline Both & 2 & 14.3 & 0 & 0.0 & 0 & 0.0 \\
\hline \multicolumn{7}{|l|}{ T1 signal: } \\
\hline Hyper & 4 & 28.6 & 0 & 0.0 & 1 & 25.0 \\
\hline Нуро & 9 & 64.3 & 3 & 100.0 & 1 & 25.0 \\
\hline Intermediate & 1 & 7.1 & 0 & 0.0 & 2 & 50.0 \\
\hline \multicolumn{7}{|l|}{ T2 signal: } \\
\hline Hyper & 10 & 71.4 & 3 & 100.0 & 2 & 50.0 \\
\hline Нуро & 2 & 14.3 & 0 & 0.0 & 0 & 0.0 \\
\hline Heterogenous & 1 & 7.1 & 0 & 0.0 & 1 & 25.0 \\
\hline Intermediate & 1 & 7.1 & 0 & 0.0 & 1 & \\
\hline
\end{tabular}

\section{Discussion}

The primary goal of imaging in the evaluation of an adnexal mass is to differentiate malignant from benign. Proper diagnoses will direct patients to the appropriate treatment algorithm to reduce the number of women unnecessarily undergoing cancer surgery, to preserve fertility in young women (by allowing laparoscopy), and, when necessary, to enable the referral of patients to a tertiary referral center with a specialist gynecologic oncologist [7].

In this study, individual analysis had been done for the MR appearance of the lesion; either cystic (unilocular or multilocular) or mixed (cystic/solid), involvement of one or both ovaries, size of the lesion, signal intensity of the tumor, enhancement of the solid component if present, wall thickness and regularity of the lesion and its enhancement, presence of vegetation and septations, their enhancement pattern and their size. MR images were analyzed for the presence of ascites, presence of infiltrated pelvic or para aortic lymph nodes, involvement of other pelvic organs and presence of peritoneal and omental deposit.

In our evaluation we first analyzed the morphology and internal components of the included ovarian cysts. The common morphologic pattern in the studied malignant lesions was the complex solid whether with septae and/or solid nodules. Purely cystic pattern was not detected in any of the included malignant ovarian masses. These results are in agreement with studies of [8-11].

In this study, conventional MRI suggested malignant pathology in three masses; all proved to be malignant. An increased risk of malignancy was related to increased size of the lesion, increased wall thickness, presence and increased size of vegetation, mixed cystic and solid configuration, intermediate to high intensity on T2-weighted imaging, presence of contrast enhancement and of ascites or peritoneal implants [4,12]. MRI also suggested borderline pathology in four masses, two of them were truly borderline tumors, while one of them was proven to be benign and the last was histopathologically proven malignant. Conventional MRI also suggested benign pathology of 14 out of the 21 studied lesions; all of them were true benign. MRI had shown $93.3 \%$ sensitivity, $100 \%$ specificity, $95.2 \%$ accuracy, $100 \%$ positive predictive value and $85.7 \%$ negative predictive value in its individual performance during the assessment of the included adnexal masses.

Bekiesi'nska-Figatowska et al., [13] had a slightly lower diagnostic accuracy of $83.3 \%$ compared with ours in which the diagnostic accuracy of MRI was 95.2\%. This difference could be explained by the different number and nature of cases included in both studies.

While Emil et al., [14] and Emad-Eldin et al., [12] results were in agreement with this study results, $93 \%$ and $92.3 \%$ diagnostic accuracy respectively. 
Other studies [15-17,20] showed relatively similar values of sensitivity and specificity similar to our study.

Throughout our study, the Borderline Tumors (BOTs) presented a challenge for us. Their morphological features can mimic benign or malignant lesions, yet they lack the invasive behavior of the malignant lesions. The preoperative diagnosis of BOTs remains challenging regarding the clinical, laboratory and imaging findings [19] . Morphological imaging features suggesting borderline tumor have been investigated; however, these overlap with those of invasive epithelial tumors. Better imaging tools are needed to improve the distinction of invasive, borderline and benign adnexal lesions [18]. This study also had some limitations concerning the small sample size and the low number of malignant and borderline lesions.

\section{Conclusion:}

Conventional MR imaging proved to exhibits high sensitivity and specificity for differentiating benign from malignant complex adnexal lesions. Conventional MRI findings as lesion morphology, signal intensity and post contrast enhancement are relatively reliable data for near accurate diagnosis.

\section{References}

1- ALLEN B.C., HOSSEINZADEH K., QASEM S.A., et al.: Practical Approach to MRI of Female Pelvic Masses, American Journal of Roentgenology, 202 (6): 1366-75, 2014.

2- FOTI P.V., ATTINÀ G., SPADOLA S., et al.: MR imaging of ovarian masses: Classification and differential diagnosis. Insights Imaging, Feb., 7 (1): 21-41, 2016.

3- PRABHA T., GOYAL S., MISHRA H.K., et al.: Role of MRI in Evaluation of Female Pelvic Masses in Comparison to Ultrasonography. Journal of Evolution of Medical and Dental Sciences, 3 (59): 13330-4, 2014.

4- VAN NIMWEGEN L.W., MAVINKURVE-GROOTHUIS A., KRIJGER R.R., et al.: MR imaging in discriminating between benign and malignant paediatric ovarian masses: A systematic review. Eur. Radiol., Feb., 30 (2): 1166-81, 2020.

5- PANCHAL S. and NAGORI C.: Ultrasound in infertility and gynecology: Text and atlas, Jaypee Brothers Medical Publishers (P) Ltd, 2019.

6- VALENTINI A.L., GUI B., MICCÒ M., et al.: Benign and suspicious ovarian masses-MR imaging criteria for characterization: Pictorial review. J. Oncol., 2012: 1-9, 2012.
7- ADUSUMILLI S., HUSSAIN H.K., CAOILI E.M., et al.: MRI of Sonographically Indeterminate Adnexal Masses. AJR, 187: 732-40, 2006.

8- BAZOT M., FIORI O. and DARAI E.: Adenomyosis in endometriosis-prevalence and impact on fertility. Evidence from magnetic resonance imaging, Human Reproduction, 21 (4): 1101-2, 2006.

9- RAJKOTIA K., VEERAMANI M. and MACURA K.J.: Magnetic Resonance Imaging of AdnexalMasses, Topics in Magnetic Resonance Imaging, 17 (6): 379-97, 2006.

10- MOYLE P.L., KATAOKA M.Y., NAKAI A., et al.: Nonovarian Cystic Lesions of the Pelvis, RadioGraphics, 30: 921-38, 2010.

11- SHAABAN A.M. and REZVANI M.: Ovarian Cancer: Detection and Radiologic Staging, Clinical Obstetrics and Gynecology, 52 (1): 73-93, 2009.

12- EMAD-ELDIN S., GRACE M.N., WAHBA M.H., et al.: The diagnostic potential of diffusion weighted and dynamic contrast enhanced MR imaging in the characterization of complex ovarian lesions. The Egyptian Journal of Radiology and Nuclear Medicine, 49: 884-91, 2018.

13- BEKIESINSKA-FIGATOWSKA M., JURKIEWICZ E., IWANOWSKA B., et al.: Magnetic resonance imaging as a diagnostic tool in case of ovarian masses in girls and young women. Med. Sci. Monit., 13 (Suppl 1): 116-20, 2007.

14- EMIL S., YOUSSEF F., ARBASH G., et al.: The utility of magnetic resonance imaging in the diagnosis and management of pediatric benign ovarian lesions. J. Pediatr. Surg., 53 (10): 2013-8. doi:10.1016/j.jpedsurg.2017. 12.028, 2018.

15- ZHANG H., ZHANG G.F., HE Z.Y., et al.: Prospective evaluation of 3T MRI findings for primary adnexal lesions and comparison with the final histological diagnosis. Arch. Gynecol. Obstet., 289 (2): 357-64, 2014.

16- BAZOT M., DARA I E., NASSAR-SLABA J., et al.: Value of Magnetic Resonance Imaging for the Diagnosis of Ovarian Tumors: A Review. J. Comput. Assist. Tomogr., 32: 712-23, 2008.

17- TSILI A.C., TSAMPOULAS C., ARGYROPOULOU M., et al.: Comparative evaluation of multidetector CT and MR imaging in the differentiation of adnexal masses. Eur. Radiol., 18 (5): 1049-57, 2018.

18- BERNARDIN L., DILKS P., LIYANAGE S., et al.: Effectiveness of semi-quantitative multiphase dynamic contrast-enhanced MRI as a predictor of malignancy in complex adnexal masses: Radiological and pathological correlation, Eur. Radiol., 22: 880-90, 2012.

19- MOROTTI M., VALENZANO M., JOHN D., et al.: The pre-operative diagnosis of borderline ovarian tumors: A review of current literature. Arch. Gynecol. Obstet., 23249, 2011.

20- HEMAT E.M., EL-GEBRY K.M. and ISMAIL A.A.: Quantitative multi-parametric MRI in characterization of ovarian cystic masses. J. Am. Sci., 13 (1): 93-103, 2017. 


\section{دور التقنيات المغناطيسى إنيسي \\ فى التفرقة بين إصابات الحوض التيات الكيسية عند النساء}

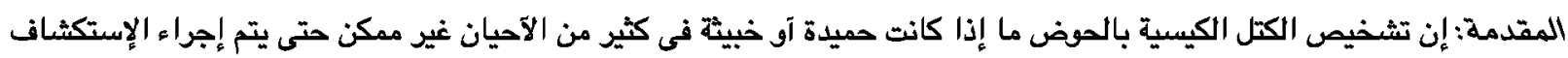
الجراحى والفحص النسيجى. ويالتالى، قد لا يكن من الممكن آن تقرد قبل الجراحة ما إذا كانت الجراحة المحافظة آو الجذرية (الإستئصال) مناسبة.

المواد والآسـاليب: آجريت دراستنا على • مريضة، خضع جميعهم للتصوير بالرنين المغناطيسى فى وحدة 1.5T.

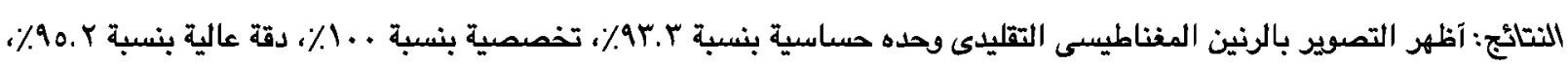

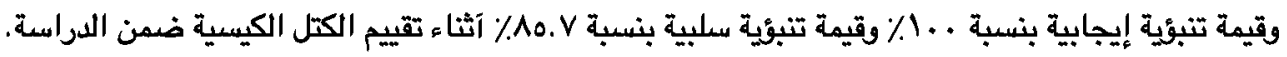
خاتمة: آثبت التصوير بالرنين المفناطيسى التقليدى آنه يظهر حساسية وتخصصية عالية التفرقة بين الكتل الكيسية الحميدة والخبية. 